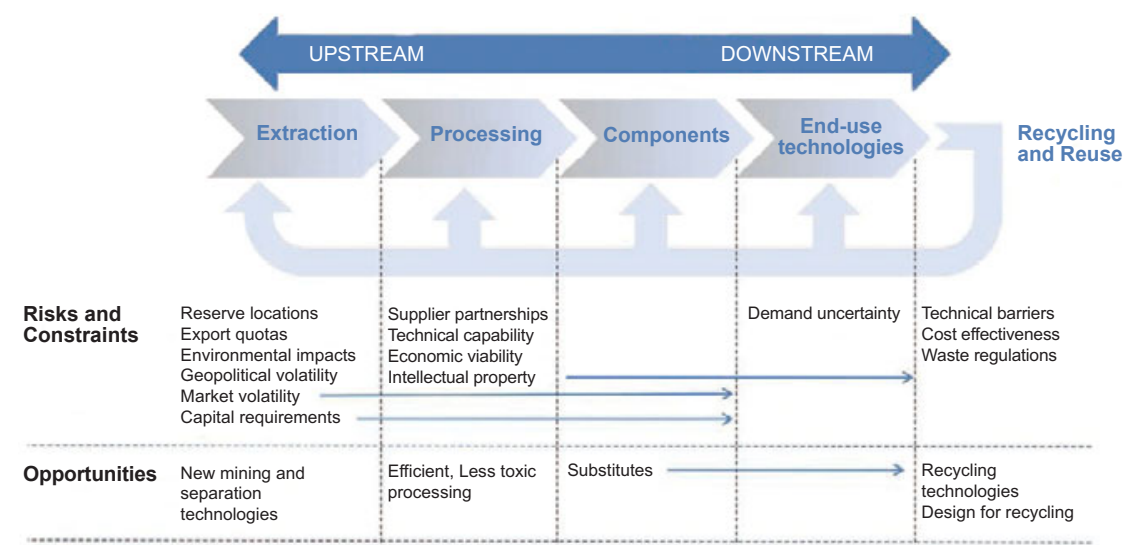

Program and policy directions and the critical material supply chain. Source: U.S. Department of Energy, Critical Materials Strategy, December 2010.

metals and other critical materials in late 2010, including a U.S.-Japan workshop, a U.S.-European Union workshop, and an Advanced Research Projects Agency-Energy (ARPA-E) workshop. "The three pillars of the strategy are globalization of supply, develop- ment of substitutes, and efficient use, and we hope that the research community can offer insight on addressing these pillars in an environmentally and economically sound way," said Bauer.

The report also cites a workforce challenge related to reducing the risks associated with critical materials. As mining, manufacturing, and materials processing has moved largely to other countries, the size of the U.S. workforce knowledgeable about rare earths and other critical materials has decreased, said Gschneidner. "We need to build up our educational capital," he said. DOE aims to do this through education and workforce training, largely in the materials sciences.

"In the years ahead, materials sciences will receive increasing attention in DOE's internships, fellowships and scholarships," reads the report. DOE will also encourage universities and laboratories to engage students and postdoctoral fellows in research related to critical materials, specifically in mineral and mining engineering, mineral economics, materials recycling technology, and manufacturing engineering.

The report can be accessed from the DOE blog at http://blog.energy.gov, posted on December 15, 2010.

\section{Kendra Redmond}

New Zealand announces members of science and innovation boards www.msi.govt.nz

n New Zealand, the Research, Science and Technology Minister Wayne Mapp announced in January the membership of the two new boards that will decide funding for science and innovation.

The Science Board and the Innovation Board will be associated with the new Ministry of Science and Innovation. The Science Board will allocate science funding to research organizations. The Innovation Board will make funding decisions related to businessfacing programs.

"These boards will be key players in the government's reforms to improve the science and innovation system," Mapp said. "They will help ensure that
New Zealand businesses are innovative, internationally competitive, and contributing to economic growth. They will fund the high-quality research needed to increase productivity and raise our standard of living."

Mapp has also appointed three new members to the Marsden Fund Council, which oversees New Zealand's premier fund for basic research.

Members to both boards and the council represent various science fields, including the physical sciences. Specifically in the materials research field is inventor and entrepreneur Grant Ryan, who has founded a number of companies, including YikeBike, GlobalBrain.net, SLI
Systems, RealContacts, and Eurekster. Ryan has a degree in mechanical engineering and $\mathrm{ahD}$ degree in ecological economics from the University of Canterbury. He was appointed to the Innovation Board.

Richard Blaikie of the University of Canterbury is director of the MacDiarmid Institute for Advanced Materials and Nanotechnology. He has been appointed to the Science Board.

David Williams, convenor of the Physics, Chemistry and Biochemistry panel for the Marsden Fund Council, is Professor of Electrochemistry at the University of Auckland. His research interests are in medical diagnostic tools, surface chemistry of oxides, electrochemistry sensors, and imaging electrochemical reactions.

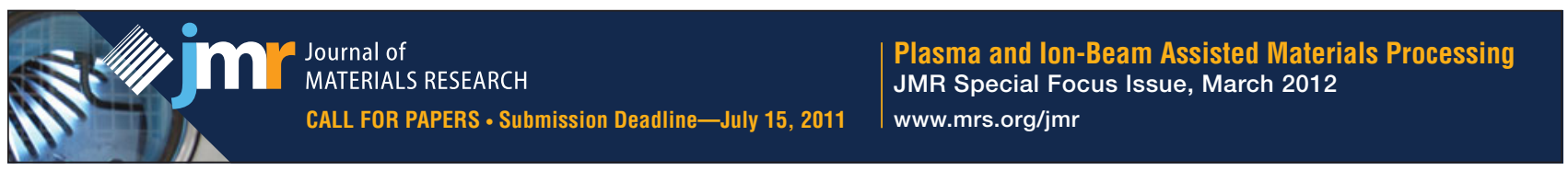


